\title{
Evaluasi Kesuksesan Sistem Informasi Kesehatan Haji di Kantor Kesehatan Pelabuhan Semarang
}

\author{
Ponco Yuniarto*, Eko Sediyono**, Farid Agushybana*** \\ * Kantor Kesehatan Pelabuhan Kelas II Semarang \\ ** Universitas Kristen Satya Wacana Salatiga \\ *** Fakultas Kesehatan Masyarakat, Universitas Diponegoro \\ Email:pyback@yahoo.com
}

\section{ABSTRACT}

This study aims to determine the success of Hajj health information system in KKP Semarang through DeLone and McLean approach. The type of this research is descriptive with a leather approach. Data collection techniques through in-depth interviews and observation. Interviews were compiled based on the DeLone and McLean Success Update model of six dimensions: system quality, information quality, service quality, usage, user satisfaction and benefits gained from using the system. The results showed that the system has a good flexibility with accessible from anywhere and the existence of export and import fascities to excel to facilitate input and report generation. The information displayed is also complete. and accurate, so as to make the user feel satisfied while using it. The lack of this system is the storage capacity that must be added because it accommodates all the existing systems in the Semarang MMAF. Benefits derived from the system is the work becomes faster and easier in recording and reporting. In addition, the results of the information can be used as material for planning by KKP Semarang

Keywords: DeLone and McLean, KKP Semarang, information system

\section{PENDAHULUAN}

Pemerintah

wajib untuk menyelenggarakan pelayanan kesehatan haji agar jemaah haji dapat melaksanakan ibadah sesuai ketentuan ajaran agama Islam. $(1,2)$ Oleh karena itu diperlukan pengelolaan pelayanan kesehatan yang didukung oleh sistem Informasi kesehatan yang mantap agar dapat menunjang pelaksanaan manajemen dan upaya kesehatan. (3) Salah satunya adalah sistem informasi kesehatan haji yang merupakan rangkaian kegiatan dalam pengelolaan data dan informasi kesehatan haji yang dimanfaatkan sebagai data surveilans epidemiologi, perumusan strategi dan sebagai perencanaan program kesehatan haji. ${ }^{(2)}$

Sistem informasi kesehatan haji adalah sarana pencatatan dan pelaporan kegiatan pelayanan kesehatan haji yang menggunakan teknologi informasi. Sistem yang didukung teknologi informasi dapat memberikan nilai tambah bagi organisasi jika didesain menjadi sistem informasi yang efisien dan efektif. ${ }^{(4)}$ Apabila Informasi diharapkan dapat sesuai dengan keperluan manajemen dan manajer, maka haruslah dirancang suatu sistem informasi manajemen (SIM) yang baik, sehingga dapat digunakan oleh manajemen sebagai 
pendukung pengambilan keputusan. ${ }^{(4)}$ Oleh karena itu perlu dilakukan evaluasi terhadap suatu sistem informasi untuk mengetahui keberhasilan suatu sistem menurut pengguna. Salah satu model evaluasi tentang kesuksesan sistem informasi adalah model DeLone and McLean dimana sistem ini dipakai oleh banyak peneliti untuk meneliti tentang keberhasilan suatu sistem informasi.

Salah satu diantaranya adalah penelitian oleh Hesham A. Baraka dan Hoda A. Baraka (2013) dengan model DeLone and McLean terhadap sistem informasi call center, bahwa keberhasilan sutau sistem informasi dipengaruhi oleh manfaat dan kepuasan pengguna yang mempunyai pengaruh terhadap sistem informasi call center. $^{(5)}$ Selain itu penelitian oleh Claus Bossen dan Flemming Witt (2013) tentang pengukuran kesuksesan sistem informasi EHR, diperoleh hasil Dari survey awal diketahui bahwa sistem ini telah dapat menghasilkan laporan tentang kesehatan haji, namun masih ada laporan yang dibuat secara manual. Selain itu kadangkadang koneksi internet yang lambat meskipun bandwith koneksi internet sudah besar. Server menampung banyak sistem yang memiliki database yang besar, yaitu sistem kesehatan haji dan sistem jemaah umroh yang dimiliki KKP Semarangbahwa sistem informasi EHR sangat handal dari segi waktu respon dan didukung oleh seluruh staf. ${ }^{(6)}$

Oleh karena itu sistem akan di evaluasi dengan metode DeLone and McLean untuk mengetahui kesuksesan dalm mendukung kegiatan haji.

\section{METODE PENELITIAN}

Penelitian ini adalah penelitian deskriptif dengan pendekatan secara kualitatif. Populasi dalam penelitian kualitatif disebut sebagai subjek penelitian. Secara spesifik, subjek penelitian disebut sebagai informan. ${ }^{(16)}$ Informan merupakan orang yang dimanfaatkan untuk memberikan informasi tentang situasi dan latar penelitian. $^{(17)}$

Informan utama dalam penelitan ini adalah petugas yang menggunakan sistem informasi kesehatan haji secara langsung sejumlah 7 (tujuh) orang. Dan informan triangulasi sebanyak 3 (tiga) orang yang terdiri dari Kepala Kantor, Kepala Seksi UKLW dan pihak ketiga (vendor). Triangulasi adalah teknik untuk keperluan pengecekan atau sebagai pembanding yang biasanya dilakukan dengan pemeriksaan melalui sumber lainnya. ${ }^{(18)}$

Data dikumpulkan melalui wawancara terhadap informan utama dan informan triangulasi. Wawancara terhadap informan utama dilakukan untuk mengetahui kesuksesan sistem informasi haji dalam dukungannya terhadap organisasi dan wawancara terhadap informan triangulasi untuk membandingkan dan mengecek keabsahan informasi dari informan utama. Pengolahan dan analisis pada penelitian ini menggunakan metode analisis isi (content analysis) yaitu pembahasan terhadap suatu informasi yang dengan cara pengumpulan informasi wawancara, kemudian direduksi dan diverifikasi dilanjutkan dengan penyajian data dan pengambilan kesimpulan. ${ }^{(19)}$

\section{HASIL DAN PEMBAHASAN \\ Kualitas Sistem}

Kualitas sistem dapat ditinjau dari fleksibilitas sistem, kecepatan dan keamanan. ${ }^{(10)}$ Fleksibilitas sistem adalah kemampuan sistem untuk beradaptasi dengan pengguna sehingga mudah diterima dan digunakan dalam input dan pembuatan laporan. ${ }^{(6)}$ Menurut pengguna sistem memiliki kemampuan untuk impor dan ekspor ke bentuk excel. Fasilitas impor dari excel dilakukan untuk mempermudah melakukan input data master yang berasal dari aplikasi siskohat Kemenag. Sedangkan fasilitas ekspor 
digunakan untuk membantu membuat laporan. Selain itu dengan berbasis web, sistem juga dapat diakses dari mana-mana asalkan ada koneksi internet dan browser untuk membukanya. Kekurangan pada fleksibilitas sistem adalah alamat yang masih menggunakan IP address. Namun Hal tersebut diatasi dengan menyimpan alamat tersebut melalui bookmark yang merupakan fasilitas pada browser. Sehingga pada saat memanggilnya tinggal membuka bookmark tersebut. Aturan penulisan alamat web umumnya menggunakan DNS (domain name server) dimana IP address akan dirubah menjadi DNS karena IP address bisa saja berubah, tapi DNS tidak akan berubah. DNS adalah nama yang biasa digunakan dalam pengalamatan web, contohnya seperti google.com, detik.com dan sebagainya. ${ }^{(20,}$ 21)

Kecepatan respon dari sistem menurut pengguna cukup cepat dan jarang menemui masalah. Masalah yang timbul berasal dari koneksi internet yang lambat bukan dari perangkat lunak itu sendiri. Koneksi internet yang lambat bisa berasal dari

bandwith jaringan yang kecil ataupun kapasitas penyimapan database yang kurang. Karena database yang besar juga mempengaruhi kecepatan akses sistem. ${ }^{(22)}$ Dari segi keamanan, dalam mengaksesnya sistem menggunakan username dan password yang terenkripsi untuk membatasi pengguna yang akan memakai sistem. Enkripsi dalam bidang kriptografi digunakan untuk mengamankan suatu informasi dimana untuk membacanya memerlukan pengetahuan khusus. Pada sistem informasi enkripsi digunakan untuk pengamanan password agar tidak mudah ditebak oleh orang lain. ${ }^{(23,}{ }^{24)}$ Selain penggunaan password, juga digunakan backup data secara berkala. Dengan adanya backup data, kemananan data menjadi lebih terjamin. Salah satu cara terbaik dalam pengamanan data pada sistem informasi adalah penggunaan backup data. ${ }^{(24)}$

\section{Kualitas Informasi}

Kualitas informasi merujuk pada output dari sistem informasi. Kualitas informasi berfokus pada informasi yang dihasilkan sistem informasi. ${ }^{(9)}$ Kualitas informasi dapat dilihat dari aspek relevan, terkini, akurat, lengkap dan kehandalan. ${ }^{(10)}$ Informasi yang dihasilkan dari sistem sudah cukup relevan dengan kebutuhan pengguna. Karena informasi sangat mendukung dalam pelaksanaan kegiatan pelayanan kesehatan haji di embarkasi.

Keakuratan juga merupakan faktor yang dinilai dari dalam kualitas informasi. Input data yang tidak akurat ke dalam satu modul akan berdampak buruk terhadap modul lainnya. Keakuratan ini karena adanya penggunaan barcode terhadap buku kesehatan jemaah haji. Jika keliru dalam memasukkan data tentang kondisi jemaah calon haji, maka dapat berakibat buruk terhadap status kesehatan tersebut. Bisa saja jemaah tersebut ditunda keberangkatannya. Selain itu jumlah jemaah calon haji yang sudah diperiksa dan belum diperiksa dapat segera diketahui. Selain keakuratan, kelengkapan juga faktor penting pada kualitas informasi.

Kelengkapan ini memudahkan petugas untuk melayani jemaah calon haji selama di embarkasi dan melakukan tindakan yang diperlukan terhadap kondisi jemaah calon haji tersebut. Dengan kelengkapan informasi yang dihasilkan, pengambilan keputusan dapat dilakukan secara cepat dan tepat.

Kehandalan informasi yang dihasilkan sistem informasi membuat sistem ini terkadang diapakai sebagai acuan terutama untuk menghitung selisih jumah jemaah calon jemaah yang berada di embarkasi baik dari segi jumlah maupun jenis kelamin. Karena data master dari Kemenag bisa berbeda dengan yang ada di lapangan. Kelemahan pada kualitas informasi ini adalah belum semua laporan dapat dicetak dalam bentuk grafik, sehingga harus dibuat dengan cara ekspor ke dalam bentuk excel karena pada saat 
pembuatan sistem belum terpikirkan kebutuhannya

\section{Kualitas Layanan}

Kualitas layanan merupakan keseluruhan dukungan yang ditawarkan oleh penyedia layanan terhadap pengguna untuk memastikan agar sistem ini dapat berjalan dengan lancar dan juga dilihat dari segi perlengkapan fisik. Kualitas layanan ini dipengaruhi oleh wujud (hardware dan software), jaminan dan responsif atau kecepatan tanggap dari pihak ketiga. ${ }^{(9)}$ Dari segi wujud, spesifikasi server yang digunakan sudah memenuhi syarat, namun kapasitas penyimpanan database kurang besar. Karena menampung database besar yang berasal dari lebih dari satu sistem informasi yang dimiliki KKP Semarang. Oleh karena itu memerlukan penambahan kapasitas untuk membagi database sistem informasi KKP Semarang. Dengan database yang besar, akan mengakibatkan akses menjadi lambat. ${ }^{(2)}$ Untuk koneksi internet, KKP Semarang menggunakan ISP dan berlangganan sebesar $20 \mathrm{Mbps}$ yang dianggarkan setiap tahun. Namun pada kegiatan embarkasi haji, bandwith tersebut ditambah sesuai kebutuhan. Hal tersebut dituangkan ke dalam kontrak. Pihak ketiga memberikan jaminan dan respon yang cepat terhadap permasalahan yang dihadapi pengguna dalam menggunakan sistem. Kecepatan respon dari pihak ketiga dalam menanggapi permasalahan tidak lebih dari 24 jam dan jaminan sistem berjalan lancar juga dibuktikan saat kegiatan operasional embarkasi haji dilaksanakan.

2. Penggunaan

Penggunaan merupakan salah satu dimensi yang digunakan untuk menguji kesuksesan sistem informasi yaitu bagaimana seringnya pengguna bekerja dan ketergantungannya terhadap sistem informasi ini. ${ }^{(9)}$ Penggunaan sistem informasi kesehatan haji selain mendukung di embarkasi, hasilnya juga digunakan

untuk input data ke Siskohat Kemenkes. Sistem informasi kesehatan haji dalam proses memasukkan datanya dilaksanakan selama embarkasi haji dan hampir digunakan selama 24 jam. Ketergantungan pengguna terhadap sistem juga cukup tinggi karena pencatatan dan pelaporan dari sistem mempermudah pengguna dalam menghasilkan informasi yang lengkap dan akurat. Pengguna mudah untuk mengetahui status kesehatan jemaah calon haji selama di embarkasi.

\section{Kepuasan Pengguna}

Kepuasan pengguna merupakan persepsi pengguna sistem yang diperoleh dari pengalaman pengguna dalam menggunakan sistem. Menurut Kotler kepuasan pengguna adalah

perasaan senang atau kecewa yang dirasakan sesorang dengan kata lain kepuasan sebagai evaluasi paska konsumsi yang dipilih setidaknya memenuhi atau melebihi harapan. ${ }^{(25)}$ Menurut pengguna dengan adanya sistem, pekerjaan menjadi lebih mudah dan cepat selesai. Pembuatan pada layar televisi memudahkan untuk melihat informasi terkini. Dengan adanya impor dari excel juga memudahkan pengguna untuk memasukkan data jika koneksi internet lambat.

4. Manfaat

Penggunaan dan kepuasan pengguna terhadap sistem memberikan dampak positif dalam peningkatan efisiensi dan efektifitas pekerjaan. Hal ini dapat dilihat bahwa pekerjaan menjadi lebih cepat dibandingkan waktu menggunakan sistem dari pusat dan pembuatan laporan juga menjadi lebih mudah. Selain itu sistem juga mempunyai manfaat bagi organisasi untuk perencanaan dalam menyusun program tentang kebutuhan saat embarkasi dan sebagai informasi tentang jenis penyakit dan faktor risiko kondisi jemaah haji dari masing-masing daerah sehingga dapat dipakai oleh dinas kesehatan sebagai 
bahan evaluasi untuk dapat mempersiapkan jemaah calon haji pada tahun berikutnya dapat mandiri dalam mempersiapkan kebutuhan laporan menjadi lebih cepat dibandingkan dengan Siskohat Kemenkes dan pelacakan jemaah yang belum diperiksa menjadi lebih cepat. Selain itu adanya tampilan yang diperlukan bagi kesehatannya.

\section{Kesimpulan}

Dari hasil penelitian yang telah dilakukan dapat disimpulkan evaluasi sistem informasi kesehatan haji dengan model DeLone and McLean dapat dinyatakan sukses. Pengguna mempersepsikan sistem secara positif dimana sistem dapat diakses asalkan ada koneksi internet dan browser, adanya fasilitas ekspor dan impor ke excel memudahkan pengguna dalam proses input dan membuat laporan sesuai kebutuhan, memudahkan proses pelacakan jemaah yang belum diperiksa, informasi dari sistem sebagai acuan jemaah yang telah diperiksa, jaminan dan respon dari pihak ketiga yang cepat dalam menangani masalah yang muncul dan adanya tampilan pada layar televise yang menampilan informasi terkini untuk umum. Hal penting yang harus segera ditangani adalah penambahan kapasitas penyimpanan database agar akses sistem dapat berjalan dengan lancar.

\section{DAFTAR PUSTAKA}

1. Undang-undang Republik Indonesia Nomor 13 Tahun 2008 tentang Penyelenggaraan Ibadah Haji. Jakarta.

2. Peraturan Mneteri Kesehatan Nomor 62 Tahun 2016 tentang Penyelenggaraan Ibadah Haji. Jakarta.

3. Undang-undang Republik Indonesia Nomor 36 Tahun 2009 tentang Kesehatan. Jakarta.

4. Furukawa, M., Minami. A., A study of the flexibility of information system
(Part 1): why do they need to be flexible? International Journal of Business and Managemnet. 2013; 8(20): 48-61.

5. Baraka HA, El-Gamily IH. Assesing call center's success: a validation of the DeLone and McLean model for information system. Egyptian Informatics Journal. 2013; 14: 99108.

6. Bossen C, Jensen LG, Udsen FW. Evaluation of comprehensive HER based on the DeLoen and McLean model for IS success: approach, result and success factors. International Journal of Medical Informatics. 2013; 82(9): 40-53

7. Eom S, editor: Testing the Seddon modelof information system success in an e-learning context: implications for evaluating DSS. 2013. Berlin, Heidelberg: Springer Berlin Heidelberg.

8. DeLone, McLean. Information system success: the quest for the dependent

variable. Information

3(1): 60-95.

System Research. 1992;

9. DeLone, McLean. The DeLone and McLean model information system success: ten year update. Journal of Management Informatics System. 2003; 19(4): 9-30.

10. Iivari J. Empirical test of the model information system success. DATABASE for Advances in Information System. 2005; 36(2): 827.

11. Bailey, James E, Pearson. Development of tool for measuring and analyzing computer user satisfaction. Management Science. 1983; 29(5): 530-545.

12. Rai, Arun, Sandra S, Lang, Welker RB. Assessing the validity of IS success models: an empirical test and theoretical analysis. Information System Research. 2002; 13(1): 50-69.

13. Rivard S, Poirier G, Raymond L, 
Bergeron F. Development of measureto assess the qualityof userdeveloped application. Database for Advances in Information Systems. 1997; 28(3): 44-58.

14. $\mathrm{Wu} \mathrm{JH}$, Wang YM. Measuring ERP Success: the key user's view. International Journal of Operation and Production Management. 2006; 26(8): 1582-1596. Stockdale R, Standing C. An interpretive approach to evaluating information system: a content, context, process framework. Europan Journal of Operational Research. 2006; 173: 1909-1102.

15. Swarjaka. Metodelogi Penelitian Kesehatan. Yogyakarta: Andi Offset; 2012.

16. Prastowo. Metode Penelitian Kualitatif dalam Perspektif Rancangan Penelitian. Cetakan II. Jakarta: Andi; 2012.

17. Moloeng. Metode Penelitian Kualitatif. Bandung: Alfabeta; 2007.

18. Sugiyono. Konsep dan Penerapan Metodologi Penelitian Ilmu Keperawatan. Surabaya: Salemba Medika: 2008.

19. Tedyana A, Kurniati R. Membuat web server mengunakan dynamic domain name server pada IP dinamis. Jurnal Teknologi Informasi \& Komunikasi Digital Zone. 2016; 7(1): 1-10.

20. Melwin S. Pengantar Jaringan Komputer. Yogyakarta: AMIKOM Yogyakarta; 2005.

21. Dahria M. Analisis kecepatan akses data dengan menggunakan koneksi ODBC dan OLE DB untuk efisiensi databse. Jurnal SAINTIKOM. 2011; 10(2): 75-90.

Rahardja U, Setiatmi V. Global password untuk kemudahan di dalam penggunaan, pengontrolan dan keamanan sistem. Seminar Nasional Aplikasi Teknologi Informasi 2010 (SNATI 2010). 2019; F39-F44.
22. Arief MR. Kemanan user database. Data Manajemen Teknologi Informasi. 2011; 12(1): 28-34.

23. Kottler P, Keller KL. Manajemen Pemasaran. Edisi 13 Jakarta: Erlangga; 2009 